\title{
Modelling of transparency of Lake Baikal inferred from the Sentinel-2 Data
}

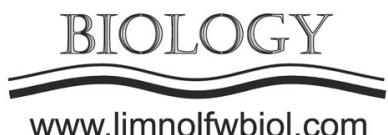

\author{
Boldanova E.V. \\ Baikal State University, Lenin Str., 11, Irkutsk, 664003, Russia
}

\begin{abstract}
The remote sensing methods usage makes it possible to increase the accuracy and efficiency of data on the state of water bodies. Among the many satellite systems, Sentinel-2 is the most suitable for inland water assessment. One of the abiotic factors in assessing the trophicity of water bodies is the transparency along the Secchi disk. Models for calculating water transparency have been developed for individual water bodies. The analysis showed that these models don't adequately describe the transparency for Lake Baikal. Based on the correlation-regression analysis, the parameters of the exponential function were estimated for calculating the transparency of the surface waters of Lake Baikal using the values of the Sentinel-2 spectral channels. Despite the inaccuracy of the model for assessing the transparency in the coastal zone, it can be used to assess the seasonal and interannual transparency of the surface waters of Lake Baikal.
\end{abstract}

Keywords: remote sensing, Secchi disk, water transparency, model, Sentinel-2, Baikal

\section{Introduction}

Field studies of reservoirs in situ are highly accurate, but they are carried out fragmentarily, most often irregularly and with low efficiency, and require high costs associated with the involvement of highly qualified specialists. The introduction of automatic ground stations for collecting information about water bodies to some extent solves these problems, but global coverage remains unavailable.

Over the past several decades, remote sensing and geographic information technology (GIS) have been successfully used in research to monitor surface water quality. This is reflected in the publications of A.A. Dontsov et al. (2017a; 2017b; 2018), S.J. Gray (1992), K. Ismail et al. (2019), and T.I. Kutyavina et al. (2019; 2020). Sensors installed on satellites and aircrafts measure the amount of radiation at different wavelengths reflected from the surface of water bodies, which is then converted into various indicators of water quality. Thanks to advances in remote sensing, parameters such as the concentration of suspended matter (TSS), chlorophyll $a$, turbidity and Secchi disk transparency (SDD) are well evaluated.

For the analysis, the data of various satellite remote sensing systems were considered on the parameters of openness, accessibility, spatial resolution, efficiency and quality of spectral channels. Today, the main competing systems for these criteria are Landsat and Sentinel (Fig. 1). Sentinel-2 is distinguished by an optimal balance of efficiency, accuracy and availability.

\section{Materials and methods}

One of the abiotic indicators of the trophicity of water bodies is the water transparency indicator using the Secchi disk. At the moment, various models have been developed to calculate the transparency of water for certain bodies of water.

For example, according to J. Delegido et al. (2019), the Secchi Disc Transparency Index (SD) is calculated as follows:

$$
\mathrm{SD}=4.7134 *(\mathrm{R} 490 / \mathrm{R} 560)^{2.5569}
$$

where R490, R560 are MSI / Sentinel-2 spectral channels with the corresponding wavelength in $\mathrm{nm}$.

Another approach to calculating transparency is described by M. Bonansea et al. (2019):

$$
S D T=1.79-134.15 * \text { Band }_{R E 1}+157.72 * \text { Band }_{N I R}+0.53 *\left(\frac{\text { Band }_{R E 3}}{\text { Band }_{N I R n}}\right)
$$

where BandRE1, BandNIR, BandRE3, BandNIR are MSI / Sentinel-2 spectral channels that have undergone atmospheric correction.

The data of the expeditions of the Limnological Institute SB RAS was used to check the data of the transparency models for the Secchi disk. Data collection was carried out during spring and autumn expeditions. The locations of the stations for determining the transparency by the Secchi disk (SD, m) are shown in Figure 2. 


\section{Comparison of Landsat 7 and 8 bands with Sentinel-2}

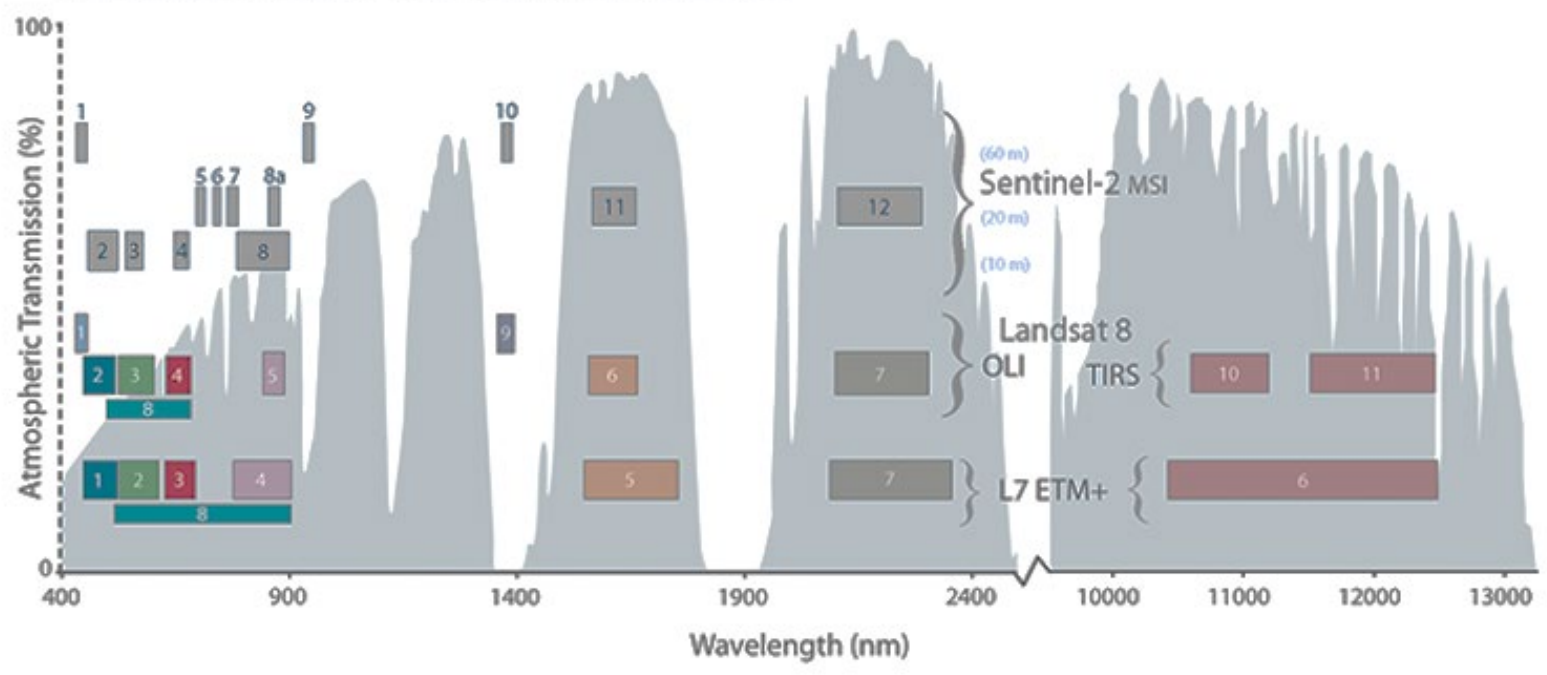

Fig.1. Comparison of Landsat 7 and 8 bands with Sentinel-2 (Image credit: U.S. Geological Survey).

Next, we selected Sentinel-2 satellite images that were close in terms of the date of measurements. Spectral channel data were extracted for further analysis. Since the researchers used linear and power dependences as models for assessing the transparency of reservoirs along the Secchi disk, the correlation dependences between the influencing factors and the studied indicator were checked.

We adapt the model suggested by J. Delegido et al. (2019) under our data. The coefficients of the model were obtained as a result of regression analysis:

$$
\mathrm{SD}=6.7327(\mathrm{~B} 02 / \mathrm{B} 03)^{0.6875}
$$

where B02, B03 are the corresponding Sentinel-2 spectral channels.

The coefficient of determination $\mathrm{R} 2=0.10$, which is considered a very low indicator, explaining that the studied indicator is described by influencing factors only by $10 \%$. Fisher's criterion indicates the reliability of the model $(6.99>3.99)$, the coefficients of the model are statistically significant according to the Student's test $(21.00>2.00 ; 2.64>2.00)$. The average relative error of approximation was $42 \%$. The results are far from those indicators of the quality of the model, which were indicated by the authors of the model.

Let's check the model of M. Bonansea et al. (2019). The coefficients of the model were obtained as a result of regression analysis:

$$
S D T=13.87-835.39 * B 05+455.87 * B 08+1.13 *\left(\frac{B 07}{B 8 A}\right)(4)
$$

where B05, B08, B07, B8A are the corresponding Sentinel-2 spectral channels.

The coefficient of determination is higher $(\mathrm{R} 2=0.40)$, Fisher's test indicates the unreliability of the model (13.97> 3.99), the last coefficient of the model is statistically insignificant according to Student's test $(0.35<2.00)$. The average relative error of approximation was 33\%. The influencing factors are very closely interconnected, which violates the requirements for building a linear model.

Difficulties with the use of existing models lead to the need to develop your own model.

\section{Results and discussion}

An assumption was made based on the analysis of correlation dependences that the exponential function using the values of the spectral channels B05 and B07 is better suited to describe these dependences.

The dependences are the closest between $\ln (\mathrm{SD})$ and the values of these spectral channels (Fig. 3).

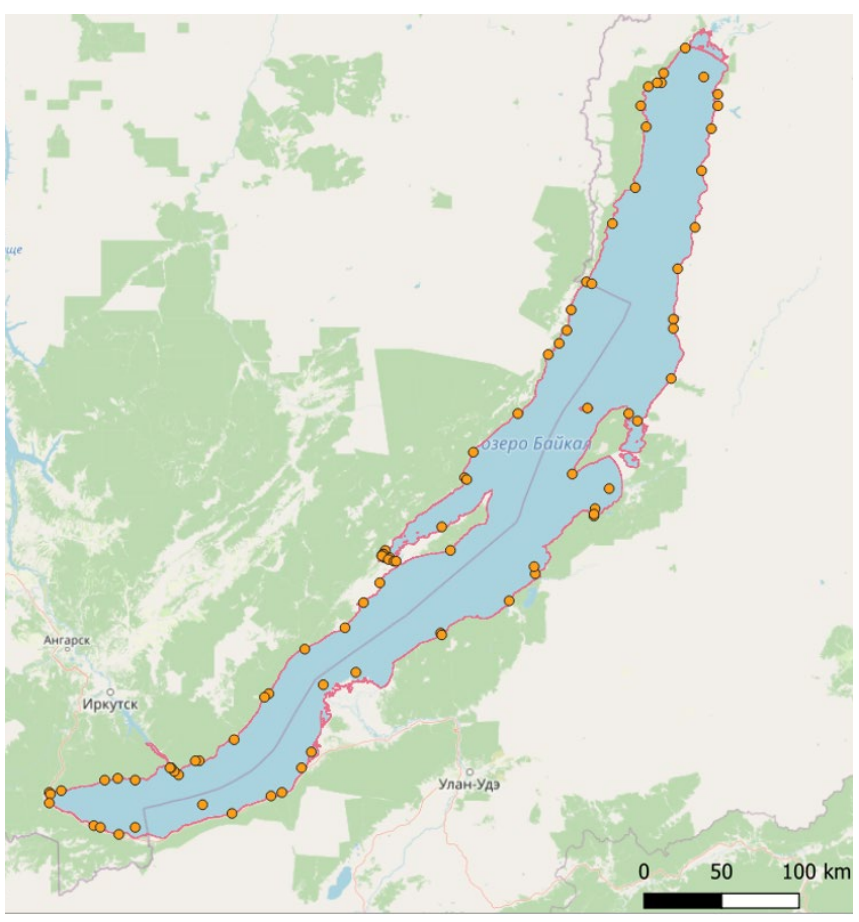

Fig.2. Locations of stations for determining the transparency by the Secchi disk (SD, m). 
The task was to estimate the parameters of an exponential function of the form:

$$
S D=a_{0} * e^{\left(a_{1} * B 05+a_{2} * B 07\right)}
$$

As a result of the regression analysis, the following model was obtained:

$$
S D=22,8158 * e^{(-142,6480 * B 05+75,0105 * B 07)}
$$

Determination coefficient $\mathrm{R} 2=0.55$. Fisher's criterion indicates the reliability of the model (38.98 $>3.99$ ), the coefficients of the model are statistically significant according to the Student's test $(23.00>2.00 ; 5.05>2.00 ; 2.89>$ 2.00). The average relative error of approximation was $29 \%$. As we can see, this model shows the best results.

This model can be used to calculate transparency for images of other periods (Fig. 4, Fig. 5).

In the future, it is possible to increase the accuracy of the model with an increase in the number of field observations.

There are disadvantages: there can be a very large error in the coastal zone. According to experts, this is influenced by a strong reflection from the bottom. In addition, the depth of the reservoir must be taken into account. This method cannot be applied to shallow water bodies.

\section{Conclusions}

It becomes possible to build transparency maps for the Secchi disk based on the obtained model on Lake Baikal during the absence of expeditions, to analyze the dynamics of this transparency change. Analysis of seasonal and interannual changes will make it possible to draw conclusions about the cyclicality, the influence of the anthropogenic factor and climatic changes.

\section{Acknowledgements}

The author is grateful to Dr. A.P. Fedotov for the materials provided by the LIN SB RAS expeditions.

\section{Conflicts of interest}

The author declare that they have no known competing financial interests or personal relationships that could have appeared to influence the work reported in this paper.

\section{References}

Bonansea M., Ledesma M., Bazán R. et al. 2019. Evaluating the feasibility of using Sentinel-2 imagery for water clarity assessment in a reservoir. Journal of
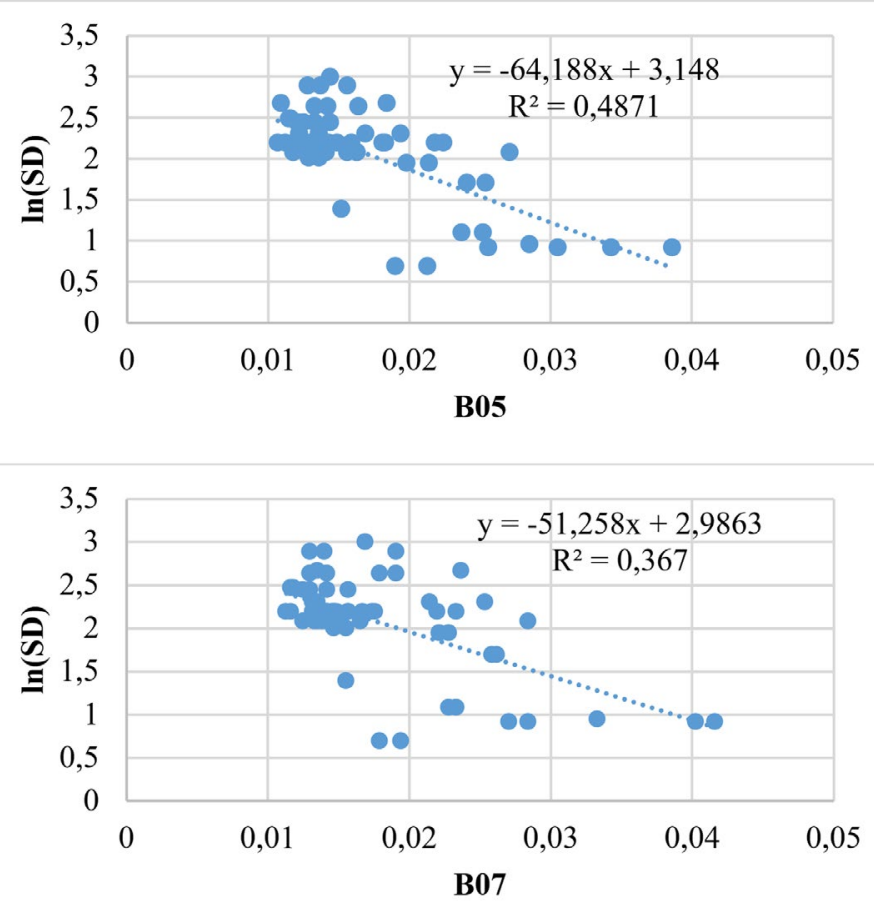

Fig.3. Relationship between ln (SD) and B05 and B07.

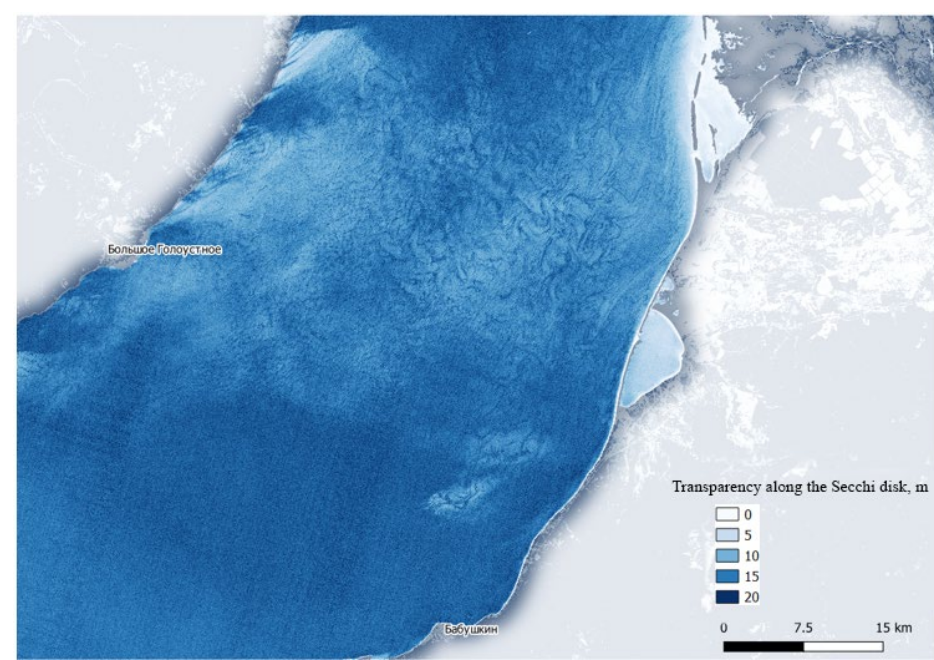

Fig.4. Transparency map using the Sentinel-2 satellite image on May 25, 2020

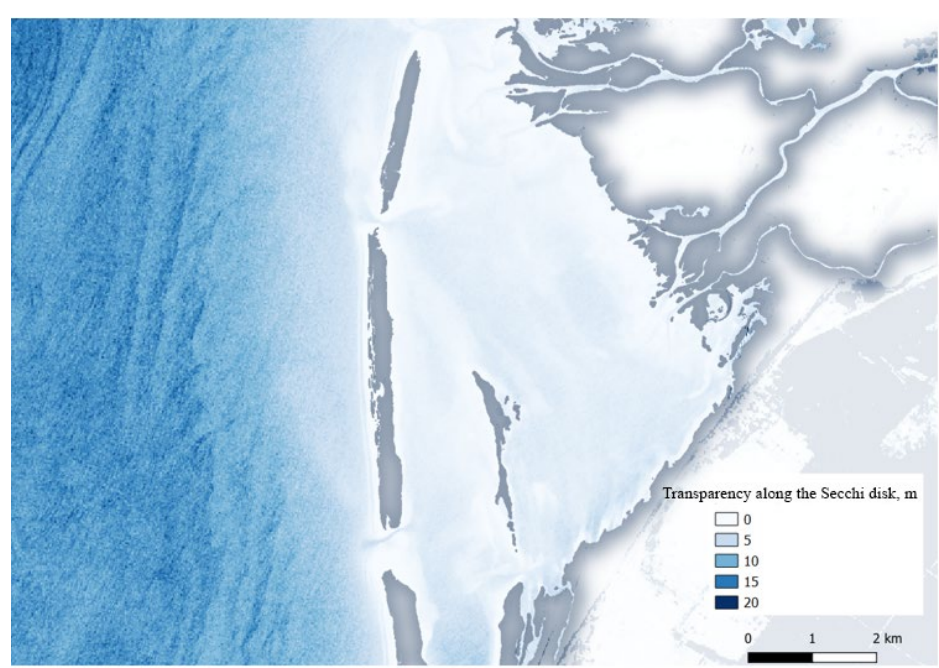

Fig.5. Fragment of transparency map using the Sentinel-2 satellite image on May 25, 2020. 
South American Earth Sciences 95: 102-265. DOI: 10.1016/j. jsames.2019.102265

Delegido J., Urrego E.P., Vicente E. et al. 2019. Turbidez y profundidad de disco de Secchi con Sentinel-2 en embalses con diferente estado tróficoen la Comunidad Valenciana. Revista de Teledetección [Remote Sensing Journal] 0(54): 15-24. DOI: $10.4995 /$ raet.2019.12603 (in Spanish)

Dontsov A.A., Pestunov I.A., Rylov S.A. et al. 2017a. Automated monitoring of the areas of water areas of lakes and reservoirs using satellite data. In: International Scientific Conference "Interexpo GEO-Siberia", pp. 38-45.

Dontsov A.A., Sutorikhin I.A. 2017b. Specialized geoinformation system for automated monitoring of rivers and reservoirs. Vychislitel'nyye Tekhnologii [Computational Technologies] 22(5): 39-46. (in Russian)

Dontsov A.A., Sutorikhin I.A. Geographic information system for registration of hydrological parameters of inland water bodies. 2018. In: International Scientific Conference "Interexpo GEO-Siberia", pp. 74-80.

Gray J.S. Eutrophication in the Sea. 1992. In: Colombo G., Ferrari I., Ceccherelli V.U. et al. (Eds.), Marine eutrophication and population dynamics: Proceedings of 25th European
Marine Biology Symposium. Fredensborg: Olsen and Olsen, pp. 3-16.

Ismail K., Boudhar A., Abdelkrim A. et al. 2019. Evaluating the potential of Sentinel-2 satellite images for water quality characterization of artificial reservoirs: The Bin El Ouidane Reservoir case study (Morocco). Meteorology, Hydrology and Water Management 7: 31-39. DOI: $10.26491 / \mathrm{mhwm} / 95087$

Kutyavina T.I., Rutman V.V., Ashikhmina T.Ya. et al. 2019. The use of satellite images to determine the boundaries of water bodies and study the processes of eutrophication. Teoreticheskaya i Prikladnaya Ekologiya [Theoretical and Applied Ecology] 3: 28-33. DOI: 10.25750/1995-4301-20193-028-033 (in Russian)

Kutyavina T.I., Kantor G.Ya., Ashikhmina T.Ya. et al. 2020. Application of methods for processing and analysis of satellite images for the study of eutrophied reservoirs (review). Teoreticheskaya i Prikladnaya Ekologiya [Theoretical and Applied Ecology] 2: 14-25. DOI: 10.25750/1995-4301-20202-014-025 (in Russian)

U.S. Geological Survey (URL: https://landsat.gsfc.nasa. gov/wp-content/uploads/2015/06/Landsat.v.Sentinel-2.png) 